\title{
The epidemiology of malaria and anaemia in the Bonikro mining area, central Côte d'Ivoire
}

\author{
Astrid M Knoblauch ${ }^{1,2,3}$, Mirko S Winkler ${ }^{1,2}$, Colleen Archer ${ }^{4}$, Mark J Divall ${ }^{3}$, Milka Owuor ${ }^{3}$, Raoul M Yapo ${ }^{5}$, \\ Pokou A Yao and Jürg Utzinger ${ }^{1,2^{*}}$
}

\begin{abstract}
Background: The epidemiology of malaria and anaemia is characterized by small-scale spatial and temporal heterogeneity, which might be influenced by human activities, such as mining and related disturbance of the environment. Private sector involvement holds promise to foster public health, including the prevention and control of malaria and anaemia. Here, results from a cross-sectional epidemiological survey, conducted in communities that might potentially be affected by the Bonikro Gold Mine (BGM) in Côte d'Ivoire, are reported.
\end{abstract}

Methods: In December 2012, a cross-sectional survey was carried out in seven communities situated within a 20-km radius of the BGM in central Côte d'Ivoire. Capillary blood samples were obtained from children aged six to 59 months. Samples were subjected to a rapid diagnostic test (RDT) for Plasmodium falciparum detection, whilst haemoglobin (Hb) was measured to determine anaemia. Additionally, mothers were interviewed with a malaria-related knowledge, attitudes and practices questionnaire.

Results: A total of 339 children and 235 mothers participated in the surveys. A positive RDT for P. falciparum was found in $69 \%$ of the children, whilst $72 \%$ of the children were anaemic $(\mathrm{Hb}<11 \mathrm{~g} / \mathrm{dl})$. Plasmodium falciparum infection was significantly associated with anaemia (odds ratio (OR) 7.43, 95\% confidence interval (CI) 3.97-13.89), access to a health facility (OR 5.59, 95\% Cl 1.81-17.32) and age (OR $0.04,95 \% \mathrm{Cl} 0.01-0.12$; youngest (six to 11 months) versus oldest (48-59 months) age group). Less than a quarter of mothers knew that malaria is uniquely transmitted by mosquitoes (22.3\%, 95\% Cl 16.8-27.7\%). Misconceptions were common; most of the mothers believe that working in the sun can cause malaria.

Conclusions: Malaria and anaemia are highly endemic in the surveyed communities around the BGM project area in Côte d'Ivoire. The data presented here provide a rationale for designing setting-specific interventions and can be utilized as a benchmark for longitudinal monitoring of potential project-related impacts due to changes in the social-ecological and health systems.

Keywords: Malaria, Anaemia, Plasmodium falciparum, Mining, Private sector, Côte d'Ivoire

\section{Background}

The extractive industry, especially mining, is an important economic sector in many African countries [1]. Meanwhile, Africa is the continent most heavily affected by malaria, which drains the social and economic development [2-4]. Knowledge about whether and to what extent the epidemiology of malaria is altered in the face of

\footnotetext{
* Correspondence: juerg.utzinger@unibas.ch

'Department of Epidemiology and Public Health, Swiss Tropical and Public Health Institute, P.O. Box CH-4002 Basel, Switzerland

${ }^{2}$ University of Basel, P.O. Box, CH-4003 Basel, Switzerland

Full list of author information is available at the end of the article
}

extractive industry projects in high endemicity areas is limited. Mining and other natural resources development and management projects are believed to influence local disease patterns, including malaria, through a variety of proximal and distal factors. For example, environmental manipulation to accommodate project-related infrastructure developments can create favourable habitats for malaria vectors, most importantly Anopheles gambiae [5,6]. Mining projects attract workers and camp followers who might live in poorly constructed houses with inadequate sanitation. Lack of drainage, along with peri-urban water bodies (e.g. swamps), might increase 
vector breeding and human-vector contact $[7,8]$. On the other hand, mining projects create opportunities for the prevention and control of malaria as the companies have an interest in keeping their workforce healthy, and thus productive. This may, at the same time, positively impact on surrounding communities, as has been shown in the Zambian copperbelt in the 1930s and 1940s, and elsewhere $[9,10]$. Moreover, corporate social responsibility has become part of international good practice for companies operating in resource-constraint settings [11]. In remote areas in developing countries, where health systems are notoriously weak and understaffed, the success of national control efforts depends on the coordination and communication among different stakeholders (e.g. government, non-governmental organizations, international institutions and the private sector) [12,13]. In such settings, the private sector can play a pivotal role in fostering public health, as emphasized by the World Health Organization (WHO) [14].

The Bonikro Gold Mine (BGM) project in central Côte d'Ivoire is planning malaria control efforts to mitigate health risks of the workforce, but is simultaneously exploring opportunities to support sustainable development initiatives in the communities surrounding the BGM project. However, there was a paucity of data regarding malaria prevalence, vector and parasite species composition and insecticide resistance in the project area. As this limited the ability to design control interventions, studies were commissioned on the following grounds: (i) the malaria prevalence is showing smallscale spatial heterogeneity [15-18]; (ii) a deeper understanding of the epidemiology of malaria in the study area will facilitate the development of targeted interventions [19]; and (iii) a detailed characterization of the baseline situation allows for longitudinal monitoring and evaluation of project impacts [20], and malaria-specific interventions. Additionally, the concurrent assessment of anaemia was considered important, as it serves as an indicator for general health and well-being [21-23].

Against this background, the following activities were undertaken: (i) a malaria and anaemia prevalence survey among children aged six to 59 months to determine the prevalence of Plasmodium falciparum and the magnitude of anaemia; (ii) a knowledge, attitudes and practices (KAP) survey related to malaria among mothers; and (iii) an entomology and insecticide susceptibility survey in order to identify effective insecticides for potential indoor residual spraying (IRS) and other vector control interventions. Here, the findings of the malaria and anaemia prevalence surveys and mothers' KAP study are presented. Detailed findings of the entomology and insecticide resistance surveys will be communicated elsewhere.

\section{Methods}

\section{Ethical considerations}

Ethical clearance was obtained from the 'Comite National d'Ethique et de la Recherche' of Côte d'Ivoire (reference no. 01/MSLS/CNER-dkn). Communities were given detailed information about the purpose and procedures of the study, the extent of their involvement, the right to withdraw anytime without further obligation and to receive free treatment based on the results of the measurements or tests done. Written informed consent was obtained from all participating mothers in the questionnaire survey before conducting any interviews, which included the approval to take capillary blood samples from their children aged six to 59 months in a mobile clinic. Individuals with a $P$. falciparum infection or anaemia were treated according to national guidelines, free of charge. Children who had a positive RDT result for P. falciparum were given artesunate/amodiaquine (Camoquin Plus; Pfizer, New York, USA) for uncomplicated malaria (if no prior treatment was received). Anaemic children were provided with iron supplements (Ferrostran; Teofarma, Valle Salimbene, Italy) and severe cases were referred to health care centres. Independent of the test results, all participating children aged above three years received a multi-vitamin suspension (Alvityl; Laboratoires URGO, Chenôve Cedex, France).

\section{Study area}

The study was carried out in the health districts of Oumé and Divo in central Côte d'Ivoire. The study area comprised two major towns, Oumé and Hiré, and several smaller villages around the BGM project (between latitudes $6^{\circ} 11^{\prime}$ and $6^{\circ} 22^{\prime} \mathrm{N}$ and longitudes $5^{\circ} 17^{\prime}$ and $5^{\circ} 24^{\prime}$ W). A map of the study area, including estimated population sizes for 2011, is provided in Figure 1. The total population residing in the surveyed sentinel sites is estimated at 12,000, whereas in Oumé and Hiré, the respective neighbourhood population, not the entire urban population, was counted.

\section{Study design and household selection}

A cross-sectional household survey was carried out in December 2012, at the end of the rainy season. Based on P. falciparum prevalence rates found among young children in previous studies conducted in central and southcentral Côte d'Ivoire [16,17,24,25] and in consultation with local health staff, the prevalence of malaria in the study area was estimated at $70 \%(p=0.7)$. With a $95 \%$ level of confidence and a precision of $5 \%$, the sample size was calculated at 336 .

The sampling methodology applied was adapted to the specific project setting and was based on a sentinel survey approach. Given the considerable demographic differences in the study area (see population sizes in Figure 1), sampling proportional to size was not considered 


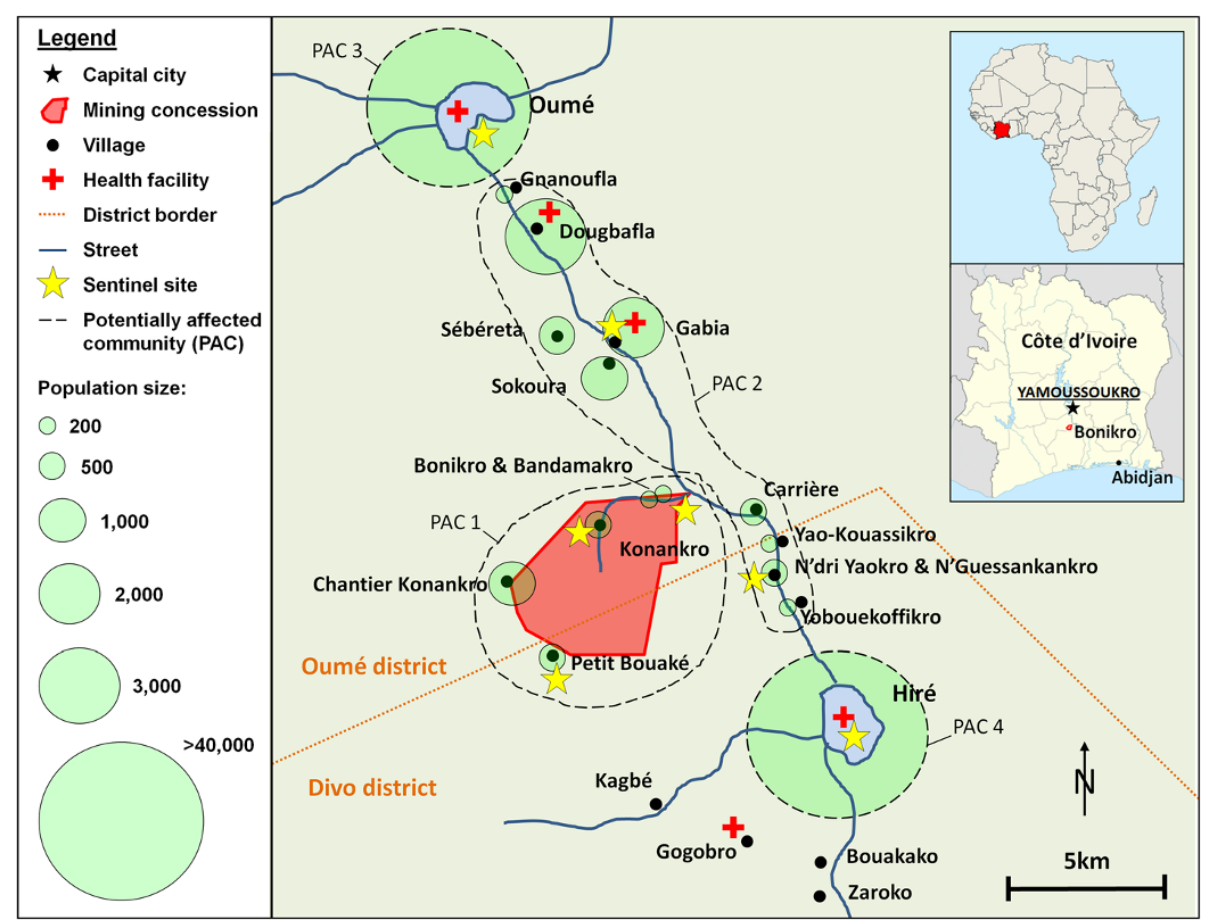

Figure 1 Study area and surveyed sentinel sites, including estimated population sizes, Côte d'Ivoire, 2012.

appropriate, as smaller villages in proximity to the project area were believed to be more directly affected by project activities than larger towns further away. Instead, villages and towns were grouped into potentially affected communities (PACs), purposely defined as specific geographical entities that are considered to be similarly impacted by project-related activities (see Figure 1, dashed line) [20]. For the BGM project, the following PACs were defined: (1) the immediate project area (potentially affected through infrastructure developments and resettlement); (2) the access road between Oumé, Hiré and the project site (potentially affected by migration and increased traffic); and (3) and (4) the urban centres of Oumé and Hiré, respectively (potentially affected through migration and potential economic shifts and representative of most of the BGM workforce). Within these four PACs that take into consideration specific project exposure, seven sentinel sites were randomly selected; thee in PAC 1 , two in PAC 2, and one each in PAC 3 and PAC 4.

Within sentinel sites, a random sampling procedure at the unit of the household was applied. Firstly, trained interviewers were sent in four random directions from a central location [20]. Secondly, interviewers counted the number of houses up to the border of the sentinel site. Thirdly, the field manager determined, through a random procedure, the first household to be interviewed in each direction. The interviewer then proceeded to interview the next household until the targeted number (minimum of 25 households per day) was achieved. The two criteria for household inclusion were: (i) household inhabited by at least one child under the age of five years; and (ii) willingness of the child's mother to respond to a questionnaire.

\section{Survey activities}

Mothers were first interviewed using a pretested KAP questionnaire. The questionnaire focussed on household demographics, malaria awareness and knowledge, modes of transmission, preventive measures, including ownership and utilization of insecticide-treated nets (ITNs), IRS and treatment-seeking behaviour for malaria. All questions were closed-ended and drawn from international standard surveys, such as Demographic and Health Surveys (DHS), to facilitate subsequent comparison with regional and national data.

Once the KAP questionnaire was completed, participating mothers were invited to bring their children aged below five years to a mobile clinic, located at a central place in each sentinel site. Capillary blood samples were collected from children aged six to 59 months. Following this, tests were conducted to determine haemoglobin $(\mathrm{Hb})$ levels using a portable HemoCue device (HemoCue $^{\odot}$ Hb 201 System; HemoCue AB, Ängelholm, Sweden) and presence of $P$. falciparum infection using an RDT (Paracheck Pf device cassette; Orchid Biomedical Systems, Goa, India). 


\section{Statistical analysis}

Data were recorded using Microsoft Excel version 2010 (Microsoft Corporation; Redmond, USA) and EpiData version 3.1 (EpiData Association; Odense, Denmark). Statistical analyses were done using Stata version 10 (StataCorp.; College Station, USA). Prevalence rates were averaged for background characteristics, such as age and sex. Adjusted odds ratios (ORs) with their corresponding 95\% confidence intervals (CIs) were calculated using multivariate logistic regression analysis for child and household attributes associated with $P$. falciparum infection and anaemia. P-values below 0.05 were considered statistically significant.

\section{Results}

\section{Study compliance and respondents' characteristics}

Overall, 574 individuals participated in the study (Figure 2). There were 242 households visited and 235 mothers had complete data records from the questionnaire survey. Without exception, mothers visited the mobile clinics, readily accompanied by their children. Overall, there were 385 children aged below five years (on average 1.44 children per mother). Among these, 339 children had a blood sample subjected to an RDT for P. falciparum and measuring $\mathrm{Hb}$ level. The mean age of the mothers interviewed was 27.9 years (standard deviation (SD), 7.4 years). Slightly more than half of the mothers $(123 / 235,52.3 \%)$ had no formal education, whereas 80 mothers $(34.0 \%)$ had primary education and the remaining 32 mothers (13.6\%) attained secondary education or higher.

\section{Plasmodium falciparum infection}

The prevalence of $P$. falciparum in children aged six to 59 months was 69.0\% (95\% CI 64.1-74.0\%) (Table 1) and varied by age. The youngest age group (six to 11 months) showed the lowest infection prevalence (47.8\%;
Table 1 Malaria prevalence by rapid diagnostic tests in children aged six to $\mathbf{5 9}$ months, stratified by sex and age group in central Côte d'lvoire in 2012

\begin{tabular}{lll}
\hline & \multicolumn{2}{l}{$\boldsymbol{P f}$ positive by RDT } \\
\cline { 2 - 3 } $\mathbf{n} / \mathbf{N}(\%)$ & $\mathbf{9 5 \% ~ C l}$ \\
\hline Sex & $112 / 164(68.3)$ & $61.1-75.5$ \\
Female & $122 / 175(69.7)$ & $62.8-76.6$ \\
Age (months) & & \\
$6-11$ & $22 / 46(47.8)$ & $32.8-62.8$ \\
$12-23$ & $52 / 80(65.0)$ & $54.3-75.7$ \\
$24-35$ & $54 / 82(65.9)$ & $55.4-76.3$ \\
$36-47$ & $54 / 69(78.3)$ & $68.3-88.2$ \\
$48-59$ & $52 / 62(83.9)$ & $74.5-93.3$ \\
Total & $234 / 339(69.0)$ & $64.1-74.0$ \\
\hline
\end{tabular}

$\mathrm{Cl}$, confidence interval; Pf, Plasmodium falciparum; RDT, rapid diagnostic test.

95\% CI 32.8-62.8\%), whilst the oldest age group had the highest prevalence (48-59 months; 83.9\%, 95\% CI 74.593.3\%). Similar prevalences were found for boys and girls.

\section{Prevalence and severity of anaemia}

The prevalence and severity of anaemia, stratified by sex and age group, are summarized in Table 2 . Anaemia, defined as $\mathrm{Hb}<11 \mathrm{~g} / \mathrm{dl}$, was recorded in $72.0 \%$ of the surveyed children. The prevalence of anaemia decreased with age $(84.8 \%$ in children aged six to 11 months; and $64.5 \%$ in children aged 48-59 months). Slightly less than half of the children were moderately anaemic ( $\mathrm{Hb} 7.0$ $9.9 \mathrm{~g} / \mathrm{dl} ; 47.5 \%)$. Severe anaemia $(\mathrm{Hb}<7 \mathrm{~g} / \mathrm{dl})$ was highest in the 24- to 35 -month-old age group (4.9\%), followed by the youngest age group (six-to 11-month-old; 4.6\%). Boys and girls were equally affected by anaemia.

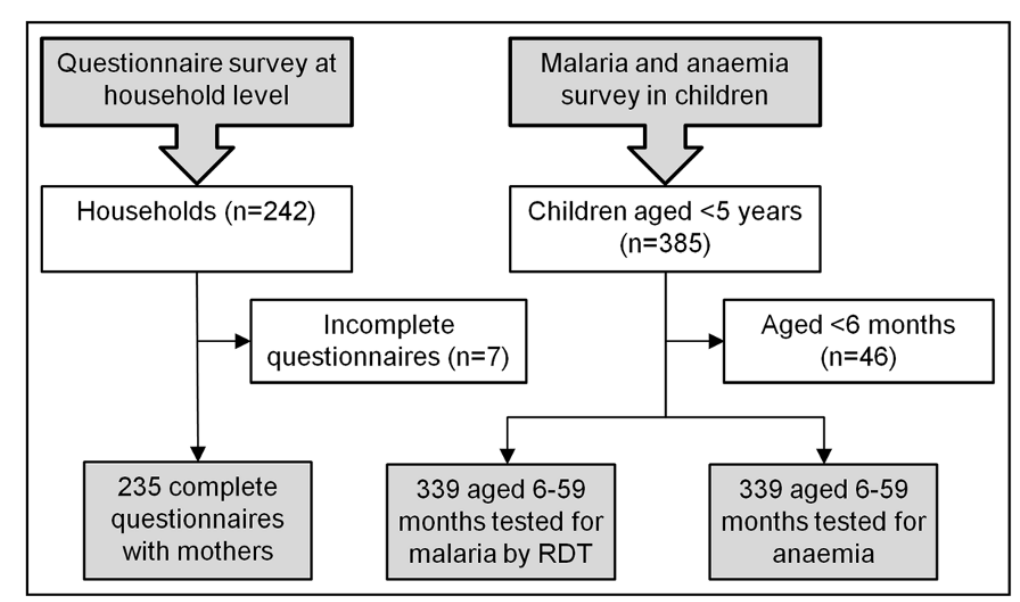

Figure 2 Study compliance. 
Table 2 Prevalence and severity of anaemia in children aged six to 59 months, stratified by sex and age group in central Côte d'Ivoire in December 2012

\begin{tabular}{|c|c|c|c|c|c|}
\hline & \multirow{2}{*}{$\begin{array}{l}\text { Mild anaemia } \\
\text { (Hb 10.0-10.9 g/dl) } \\
\mathrm{n} / \mathrm{N}(\%)\end{array}$} & \multirow{2}{*}{$\begin{array}{l}\text { Moderate anaemia } \\
\text { (Hb 7.0-9.9 g/dl) } \\
\mathrm{n} / \mathrm{N}(\%)\end{array}$} & \multirow{2}{*}{$\begin{array}{l}\text { Severe anaemia } \\
(\mathrm{Hb}<7 \mathrm{~g} / \mathrm{dl}) \\
\mathrm{n} / \mathrm{N}(\%)\end{array}$} & \multicolumn{2}{|l|}{$\begin{array}{l}\text { Any anaemia } \\
(\mathrm{Hb}<11 \mathrm{~g} / \mathrm{dl})\end{array}$} \\
\hline & & & & n/N (\%) & $95 \% \mathrm{Cl}$ \\
\hline \multicolumn{6}{|l|}{ Sex } \\
\hline Male & $31 / 164$ (18.9) & $83 / 164$ (50.6) & 4/164 (2.4) & 118/164 (72.0) & $65.0-78.9$ \\
\hline Female & 43/175 (24.6) & 78/175 (44.6) & 5/175 (2.9) & 126/175 (72.0) & $65.2-78.7$ \\
\hline \multicolumn{6}{|c|}{ Age (months) } \\
\hline $6-11$ & $7 / 46(15.2)$ & $30 / 46(65.2)$ & $2 / 46(4.6)$ & 39/46 (84.8) & 74.0-95.6 \\
\hline $12-23$ & $14 / 80(17.5)$ & 45/80 (56.3) & $2 / 80(2.5)$ & $61 / 80(76.3)$ & $66.7-85.8$ \\
\hline $24-35$ & 25/82 (30.5) & 31/82 (37.8) & 4/82 (4.9) & $60 / 82(73.2)$ & $63.4-83.0$ \\
\hline $36-47$ & 17/69 (24.6) & 27/69 (39.1) & $0 / 69(0.0)$ & 44/69 (63.8) & $52.1-75.4$ \\
\hline $48-59$ & 11/62 (17.7) & 28/62 (45.2) & 1/62 (1.6) & $40 / 62(64.5)$ & $52.3-76.8$ \\
\hline Total & $74 / 339$ (21.8) & $161 / 339(47.5)$ & $9 / 339(2.7)$ & $244 / 339(72.0)$ & $67.2-76.7$ \\
\hline
\end{tabular}

$\mathrm{Cl}$, confidence interval; $\mathrm{Hb}$, haemoglobin.

\section{Findings of the KAP survey}

Key results of the KAP survey are shown in Table 3. While awareness of malaria was high (97.5\%), knowledge of the disease was considerably lower. For example, when asked about causes of malaria, almost half of the mothers $(47.6 \%)$ mentioned - without prompting - that mosquitoes transmit malaria. However, "being in the sun" was presented as the cause of malaria by more than half of the respondents $(52.4 \%)$. Consequently, consistent knowledge on malaria transmission, i.e. malaria is solely transmitted through mosquito bites, was low (22.3\%). Similarly, mothers' knowledge pertaining to malaria prevention was poor. Possible prevention measures included "avoiding mosquito bites" (10.9\%) and "avoid exposure to the sun" (30.6\%). Most of the mothers reported to have taken intermittent preventive treatment (IPT) during their last pregnancy (87.2\%).

Among the households visited, $77.4 \%$ owned at least one ITN and the mean number of ITNs per household was 2.1 (95\% CI 1.9-2.4). Of the children below the age of five years, $61.5 \%$ slept under an ITN the night preceding the survey. The IRS coverage at household level was $10.6 \%$ (25 out of the 235 structures visited were sprayed within 12 months before the current survey).

Most of the mothers reported that they sought medical advice in a formal health facility during the last fever episode of their child (79.1\%). Additionally, use of traditional medicine was quite common; among all respondents, 39.0\% had consulted a traditional healer at some point with a sick child.

\section{Results from logistic regression analysis}

Results from the logistic regression analysis for child and household attributed factors associated with $P$. falciparum infection and anaemia are summarized in Table 4. Age was significantly associated with $P$. falciparum infection, with younger age groups having a lower odds of infection (OR, 0.04; $95 \%$ CI 0.01-0.12 for the six to 11 months age group; OR, $0.14,95 \%$ CI $0.05-0.38$ for the $12-23$ months age group; and OR, 0.17, 95\% CI 0.06-0.47 for the 24-35 months age group) compared to the oldest age group (48-59 months). There was a strong association between P. falciparum infection and $\mathrm{Hb}$ level. Children who tested $P$. falciparum positive had a more than seven-fold higher odds of being anaemic (OR, 7.43; 95\% CI 3.97-13.89) than their non-infected counterparts. Lack of access to a health care facility was positively associated with $P$. falciparum infection. Children living in villages with no health facility had a 5.59 times higher odds of $P$. falciparum infection. Consistent knowledge of respondents regarding transmission (i.e. malaria uniquely transmitted by mosquito bites) showed a negative association with $P$. falciparum infection among children (OR, 0.27; 95\% CI 0.14-0.53).

Children in sentinel sites who received an ITN through the private sector distribution campaign six months prior to the current cross-sectional survey (i.e. Bonikro, Bandamakro, Petit Bouaké and Konankro) were at about half the odds of $P$. falciparum infection when compared to the other sentinel sites (OR, 0.47; 95\% CI 0.15-1.50). Sleeping under an ITN the night preceding the survey and educational status of the mother were found to be nonsignificant ( $p>0.05$ ) for all attributes.

Child age was found to be strongly associated with anaemia. Children younger than 35 months were at a significantly higher odds of anaemia than their older counterparts. The odds for anaemia in children aged six to 11 months was eight times higher than for the oldest age group (OR, 7.98; 95\% CI 2.61-24.43). 
Table 3 Knowledge, attitudes and practices related to malaria and health-seeking behaviour among mothers aged 15-49 years in central Côte d'Ivoire in December 2012

\begin{tabular}{|c|c|c|}
\hline & $\mathrm{n} / \mathrm{N}(\%)$ & $95 \% \mathrm{Cl}$ \\
\hline \multicolumn{3}{|l|}{ Malaria awareness } \\
\hline Ever heard about malaria & 229/235 (97.5) & $94.5-99.1$ \\
\hline \multicolumn{3}{|l|}{ Malaria transmission } \\
\hline Consistent knowledge on malaria transmission ${ }^{a}$ & $51 / 229(22.3)$ & $16.8-27.7$ \\
\hline Knowledge that mosquitoes transmit malaria & 109/229 (47.6) & 41.1-54.1 \\
\hline Belief that exposure to sun can cause malaria & $120 / 229(52.4)$ & $45.9-58.9$ \\
\hline
\end{tabular}

Malaria symptoms

Fever stated as main malaria symptom

$111 / 229(48.5) \quad 41.9-55.0$

Malaria prevention

Avoid mosquito bites

25/229 (10.9) 6.8-15.0

Avoid exposure to the sun

$70 / 229(30.6) \quad 24.6-36.6$

Mothers having received IPT during the last $\quad 205 / 235$ (87.2) $\quad 82.9-91.5$ pregnancy

\section{Ownership and use of ITNs}

Mean number of ITNs per household ( $n$ )

Households owning at least one ITN

$2.1 \quad 1.9-2.4$

Children aged $<5$ years who slept under an ITN the night preceding the survey ${ }^{b}$

$182 / 235(77.4) \quad 71.6-82.6$

$235 / 382(61.5) \quad 56.4-66.4$

\section{Indoor residual spraying}

Households that had IRS within the 12 months preceding the survey

$25 / 235(10.6) \quad 7.0-15.3$

\section{Health seeking behaviour}

Mothers who sought medical advice or treatment at a formal health facility the last time the youngest child had fever ${ }^{c}$

Mothers who ever consulted a traditional healer $\quad$ 90/231 (39.0) 32.6-45.6 when child was sick ${ }^{\mathrm{d}}$

${ }^{\mathrm{a}}$ Knowing that malaria is only transmitted through mosquito bites; ${ }^{\mathrm{b}}$ includes all children aged < five years; c of all children who ever had fever; ${ }^{d}$ of all children who had ever been sick; $\mathrm{Cl}$, confidence interval; IPT $\mathrm{p}_{\mathrm{p}}$ intermittent preventive treatment during pregnancy; IRS, indoor residual spraying; ITN, insecticide-treated net.

\section{Discussion}

This study found high prevalences of $P$. falciparum $(69.0 \%)$ and anaemia (72.0\%) in children aged six to 59 months and limited knowledge on malaria transmission and prevention among children's mothers in communities located in the zone of influence of the BGM project area in central Côte d'Ivoire. The comparison of the observed $P$. falciparum prevalence with reports in previous surveys from central and south-central Côte d'Ivoire $[16-18,24,25]$ underscores that malaria is highly endemic but that small-scale heterogeneity is considerable. For example, Koudou et al. [16] conducted several crosssectional entomological and parasitological surveys in two villages in central Côte d'Ivoire (distance between the villages is approximately $80 \mathrm{~km}$ ) to better understand the transmission of malaria. In surveys conducted in August 2005, the authors found prevalences of $62 \%$ and $82 \%$ in children aged six years and below in the two study villages, as determined by Giemsa-stained blood films examined microscopically. Righetti et al. $[17,26]$ reported P. falciparum prevalences of $45.3 \%$ and $78.2 \%$ (using RDTs) among two cohorts of children consisting of (i) six- to 23-month-old infants and (ii) six- to eightyear-old schoolchildren, respectively, in three settings of the Taabo health and demographic surveillance system in south-central Côte d'Ivoire in a cross-sectional survey done in April 2010. Comparing the RDT results presented here for the same age group with data from the central-western region of Côte d'Ivoire obtained during the 2011/2012 national DHS [18] revealed a considerable difference: $69 \%$ (current study) versus $43 \%$ (DHS). The observed differences might partly be explained by seasonality $[27,28]$. However, the local socialecological contexts, potentially affected by population influx, might also play a role. For example, several studies reported an adaptation of An. gambiae to polluted water bodies $[8,29]$.

Interestingly, $P$. falciparum prevalence was found to be associated with three non-behavioural factors (i.e. anaemia status, host age and access to health care) and one behavioural factor (i.e. consistent knowledge of respondents regarding malaria transmission). The association between anaemia and malaria is widely acknowledged in the literature $[22,30]$. In the current study area, the sentinel sites that do have health facilities are somewhat more urbanized. Hence, access to health care is likely to be linked to other socio-economic and health systems factors that differ between the urban and rural settings. The fact that knowledge of malaria transmission by mothers is associated with lower odds of $P$. falciparum infection may imply that mothers who are aware of the risk take measures to protect their children, or have better treatment-seeking practices.

Anaemia was highly prevalent in the six- to 59-monthold children in this survey (72.0\%). A similarly high prevalence was found in the same age group during the recent DHS at the national level (75\%), but it is somewhat lower than the regional average for the centralwestern region (83\%) [18]. Righetti et al. [17] reported an anaemia prevalence of $78 \%$ among six- to 23 -monthold infants and $47 \%$ among schoolchildren aged six to eight years. Anaemia is multifactorial, with malnutrition, intestinal parasite infections (most importantly hookworm) and malaria being the key drivers [22,31,32]. The current study did not investigate concurrent helminth infections and micronutrient deficiencies, and hence it is not possible to quantify the differential contribution of these factors to the high rate of anaemia. The observed association of anaemia with child age has been reported before, and the proposed, underlying mechanism is that 
Table 4 Results from multivariate logistic regression analysis of child, household and mother attributes associated with malaria and anaemia

\begin{tabular}{|c|c|c|c|c|c|c|}
\hline \multirow[b]{2}{*}{ Attribute } & \multicolumn{3}{|c|}{ Malaria } & \multicolumn{3}{|c|}{ Anaemia } \\
\hline & (\%) & Adjusted $\mathrm{OR}^{\mathrm{a}}(95 \% \mathrm{Cl})$ & $p$-value & (\%) & Adjusted $\mathrm{OR}^{\mathrm{a}}(95 \% \mathrm{Cl})$ & $\mathrm{p}$-value \\
\hline \multicolumn{7}{|l|}{ Sex } \\
\hline Male & 68.3 & 1.00 & - & 72.0 & 1.00 & - \\
\hline Female & 69.7 & $1.02(0.58-1.80)$ & 0.948 & 72.0 & $1.04(0.61-1.78)$ & 0.891 \\
\hline \multicolumn{7}{|l|}{ Age (months) } \\
\hline $6-11$ & 47.8 & $0.04(0.01-0.12)$ & $<0.001^{*}$ & 84.8 & $7.98(2.61-24.43)$ & $<0.001^{*}$ \\
\hline $12-23$ & 65.0 & $0.14(0.05-0.38)$ & $<0.001^{*}$ & 76.3 & $3.10(1.34-7.20)$ & $0.008^{*}$ \\
\hline $24-35$ & 65.9 & $0.17(0.06-0.47)$ & $0.001^{*}$ & 73.2 & $2.51(1.11-5.70)$ & $0.028^{*}$ \\
\hline $36-47$ & 78.3 & $0.50(0.17-1.47)$ & 0.209 & 63.8 & $1.04(0.48-2.30)$ & 0.913 \\
\hline $48-59$ & 83.9 & 1.00 & - & 64.5 & 1.00 & - \\
\hline \multicolumn{7}{|l|}{ P. falciparum infection } \\
\hline RDT negative & - & - & - & 49.5 & 1.00 & - \\
\hline RDT positive & - & - & - & 82.1 & $7.43(3.97-13.89)$ & $<0.001^{*}$ \\
\hline \multicolumn{7}{|l|}{ ITN use ${ }^{b}$} \\
\hline Yes & 66.3 & 1.00 & - & - & - & - \\
\hline No & 73.0 & $1.50(0.83-2.69)$ & 0.180 & - & - & - \\
\hline \multicolumn{7}{|l|}{ Access to health care } \\
\hline Health facility & 57.0 & 1.00 & - & 64.9 & 1.00 & - \\
\hline No health facility & 80.5 & $5.59(1.81-17.32)$ & $0.003^{*}$ & 78.7 & $1.20(0.68-2.11)$ & 0.535 \\
\hline \multicolumn{7}{|l|}{ ITN distribution ${ }^{c}$} \\
\hline Not received & 63.5 & 1.00 & - & - & - & - \\
\hline Received & 77.9 & $0.47(0.15-1.50)$ & 0.203 & - & - & - \\
\hline \multicolumn{7}{|l|}{ Education of mother } \\
\hline Some formal education & 64.0 & 1.00 & - & 72.1 & 1.00 & - \\
\hline No formal education & 73.6 & $1.15(0.64-2.08)$ & 0.635 & 71.9 & $0.83(0.48-1.43)$ & 0.503 \\
\hline \multicolumn{7}{|c|}{ Consistent knowledge of mother $^{d}$} \\
\hline No & 76.6 & 1.00 & - & - & - & - \\
\hline Yes & 45.8 & $0.27(0.14-0.53)$ & $<0.001^{*}$ & - & - & - \\
\hline
\end{tabular}

${ }^{a}$ Multivariate logistic regression odds ratio (OR); ${ }^{b}$ children aged six to 59 months who have slept under an ITN the night preceding the survey according to the mother; chouseholds that received an ITN during the private sector ITN distribution in June 2012; ${ }^{d}$ knowing that malaria is only transmitted through mosquito bites; *significant p-value; $\mathrm{Cl}$, confidence interval; $\mathrm{Hb}$, haemoglobin; ITN, insecticide-treated net; RDT, rapid diagnostic test.

iron requirements are related to growth rate, and hence iron demand declines with age [25,33].

In Côte d'Ivoire, ITN coverage, defined as households owning at least one ITN, has been intensely scaled up from less than $10 \%$ in 2005 to $60 \%$ in 2011 [14]. After the most recent distribution campaign in 2011/2012, preceding the current survey in December 2012, the coverage of the central-western region had further increased to $77.4 \%$ according to DHS data [18]. The study area had a comparable household coverage of ITNs with $76.7 \%$, though the utilization among children below the age of five years lagged behind in both the current survey (61.5\%) and the DHS (50.6\% in central-western region) $[18,34]$. It is interesting to note that no clear association between ITN ownership and/or use and P. falciparum infection prevalence was found, but this may be explained by other confounding factors. The KAP survey highlighted important inadequacies in malariarelated knowledge, its transmission and prevention. Misconceptions on causes of malaria are common, as revealed here with more than $50 \%$ of the interviewed mothers mentioning working in the sun. On the other hand, the correct cause (i.e. transmission of malaria is uniquely due to mosquito bites) was stated by less than half of the mothers. Taken together, these findings clearly indicate that intervention campaigns of any kind (e.g. ITN distribution) and introduction of RDTs should go hand-in-hand with setting-specific information, 
education and communication (IEC) strategies in order to enhance the impact of ITNs.

In July 2012, five months prior to this survey, an entomology and insecticide resistance survey found that An. gambiae s.s. is the main vector in the study area. Wild caught female mosquitoes $(\mathrm{n}=211)$ from Oumé and Hiré towns were exposed for one hour to either $0.05 \%$ deltamethrin, $4 \%$ malathion, $0.1 \%$ bendiocarb or $4 \%$ dichlorodiphenyltrichloroethane (DDT) [35]. Mortality 24 hours after exposure was $15.1 \%$ for deltamethrin, $10.4 \%$ for malathion, $6.9 \%$ for bendiocarb and $10.5 \%$ for DDT. Further, knock-down resistance, both east and west resistance alleles, were found in $83 \%$ and $96 \%$ of mosquitoes $(n=111)$, respectively, and G119S mutations in $37 \%$. These findings confirmed earlier indications of high resistance to insecticides in Côte d'Ivoire and in neighbouring countries [36-38]. Based on these results, IRS was initiated by BGM, which led to a relatively high IRS coverage in the study area $(10.6 \%)$ compared to the regional average for the central-western region (0.5\%). All structures surveyed in Bonikro and Bandamakro were sprayed through the BGM IRS programme. Outside these sites, only two of the interviewed households reported that they had undergone IRS, resulting in an overall coverage of $0.9 \%$, which is comparable with data from the recent DHS. The combined protective effects of IRS and ITNs have been documented in the literature with some inconsistency [39,40]. Corbel and colleagues [41], for example, concluded that IRS combined with ITNs in an endemic, high pyrethroid-resistance area in Benin, had no beneficial effect. However, the combination of IRS and case management has proven successful in a malaria control programme on Bioko Island, Equatorial Guinea [42]. A significant reduction in malaria prevalence ( $42 \%$ less infections within two years) has been observed in locations where spray intervals and coverage were optimized. The programme demonstrated the benefits of collaboration between the private sector (Marathon Oil) and local government (the Government of Equatorial Guinea).

\section{Conclusion}

The surveyed communities in a major mining area of central Côte d'Ivoire are significantly affected by malaria and anaemia, whilst access to health care, IEC strategies and prevention measures are limited. The effectiveness and sustainability of malaria control interventions can be enhanced through intersectoral collaboration, including public-private partnerships. The private sector has direct business interests and social cooperate responsibility to support malaria control in the project area. The data presented here provide a rationale for settingspecific interventions. Follow-up surveys pertaining to Plasmodium infection and anaemia in the PACs will allow for long-term monitoring of potential project-related impacts pertaining to environmental and socio-economic changes and the effect of malaria control interventions, such as ITN distribution, IRS or IEC activities [20,43].

\section{Competing interests}

This study received financial support from Newcrest Mining Limited. The funder had no role in the study design, data collection and analysis, decision to publish or preparation of the manuscript. RMY and PAY were employees of Newcrest Mining Limited at the time of the survey. All other authors declare that they have no competing interests.

\section{Authors' contributions}

AMK conceived the study design and data collection of the malaria and anaemia prevalence and knowledge, attitudes and practices surveys. AMK and CA managed the field activities. MJD was the overall study coordinator. AMK and MO conducted the statistical analysis. AMK and MSW drafted the manuscript. RMY was the medical director of the study, assisted in obtaining ethical clearance and was in charge of sensitizing the local health authorities. RMY and PAY supported the sensitization of the communities and assisted with data collection. CA, MJD, MO and JU contributed to the interpretation of the data, manuscript writing and revisions. All authors read and approved the final manuscript.

\section{Acknowledgements}

We are grateful to the Comité National d'Ethique et de la Recherche of Côte d'lvoire for their interest and approval of the study. We would like to thank the authorities of Oumé and Divo health districts as well as the national malaria control programme for their indispensable support and technical assistance during the preparation, field work and laboratory investigations. The authors would like to express their gratitude to the communities that participated in the household survey. We are appreciative of the support provided by management, especially Mr Braam Beyers, and staff of Bonikro Gold Mine for the support prior, during and after the surveys.

\section{Author details}

'Department of Epidemiology and Public Health, Swiss Tropical and Public Health Institute, P.O. Box CH-4002 Basel, Switzerland. '2University of Basel, P.O. Box, CH-4003 Basel, Switzerland. ${ }^{3}$ SHAPE Consulting Ltd, Pretoria 0062, South Africa. ${ }^{4}$ University of Kwa Zulu Natal, Durban 4041, South Africa. ${ }^{5}$ Newcrest Mining Limited, Immeuble Danny Centre, II Plateaux, Vallon, Abidjan, Côte d'lvoire.

Received: 6 January 2014 Accepted: 20 May 2014

Published: 27 May 2014

\section{References}

1. UNECA: Africa Review Report on Mining (Executive Summary). Adis Ababa: United Nations Economic Commission for Africa; 2011.

2. Sachs J, Malaney P: The economic and social burden of malaria. Nature 2002, 415:680-685.

3. WHO: Global Strategic Framework for Integrated Vector Management. Geneva: World Health Organization; 2004.

4. Utzinger J, Tanner M: Socioeconomic development to fight malaria, and beyond. Lancet 2013, 382:920-922.

5. Tuno N, Okeka W, Minakawa N, Takagi M, Yan G: Survivorship of Anopheles gambiae sensu stricto (Diptera: Culicidae) larvae in western Kenya highland forest. J Med Entomol 2005, 42:270-277.

6. Afrane YA, Zhou G, Lawson BW, Githeko AK, Yan G: Effects of microclimatic changes caused by deforestation on the survivorship and reproductive fitness of Anopheles gambiae in western Kenya highlands. Am J Trop Med Hyg 2006, 74:772-778.

7. Martens P, Hall L: Malaria on the move: human population movement and malaria transmission. Emerg Infect Dis 2000, 6:103-109.

8. Awolola TS, Oduola AO, Obansa JB, Chukwurar NJ, Unyimadu JP: Anopheles gambiae s.s. breeding in polluted water bodies in urban Lagos, southwestern Nigeria. J Vector Borne Dis 2007, 44:241-244.

9. Utzinger J, Tozan Y, Doumani F, Singer BH: The economic payoffs of integrated malaria control in the Zambian copperbelt between 1930 and 1950. Trop Med Int Health 2002, 7:657-677. 
10. Roll Back Malaria Partnership, WHO: Business Investing in Malaria Control: Economic Returns and a Healthy Workforce for Africa. Geneva: World Health Organization; 2011

11. Harrison M: Beyond the fence line: corporate social responsibility. Clin Occup Environ Med 2004, 4:1-8.

12. Tobgay T, Torres CE, Na-Bangchang K: Malaria prevention and control in Bhutan: successes and challenges. Acta Trop 2011, 117:225-228.

13. Yeka A, Gasasira A, Mpimbaza A, Achan J, Nankabirwa J, Nsobya S, Staedke SG, Donnelly MJ, Wabwire-Mangen F, Talisuna A, Dorsey G, Kamya MR, Rosenthal PJ: Malaria in Uganda: challenges to control on the long road to elimination: I. Epidemiology and current control efforts. Acta Trop 2012, 121:184-195.

14. WHO: World Malaria Report 2012. Geneva: World Health Organization; 2012

15. Carter R, Mendis KN, Roberts D: Spatial targeting of interventions against malaria. Bull World Health Organ 2000, 78:1401-1411.

16. Koudou BG, Tano Y, Keiser J, Vounatsou P, Girardin O, Klero K, Koné M, N'Goran EK, Cissé G, Tanner M, Utzinger J: Effect of agricultural activities on prevalence rates, and clinical and presumptive malaria episodes in central Côte d'Ivoire. Acta Trop 2009, 111:268-274.

17. Righetti AA, Koua AYG, Adiossan LG, Glinz D, Hurrell RF, N'Goran EK, Niamké S, Wegmüller R, Utzinger J: Etiology of anemia among infants, school-aged children, and young non-pregnant women in different settings of south-central Côte d'Ivoire. Am J Trop Med Hyg 2012, 87:425-434

18. Insitut National de la Statistique: ICF International: Enquête démographique et de santé et à indicateurs multiples Côte d'lvoire (EDS-MICS) 2011-2012. Calverton, Maryland, USA: INS and ICF International; 2013.

19. WHO: Handbook for Integrated Vector Management. Geneva: World Health Organization; 2012

20. Winkler MS, Divall MJ, Krieger GR, Schmidlin S, Magassouba ML, Knoblauch AM, Singer $B H$, Utzinger J: Assessing health impacts in complex eco-epidemiological settings in the humid tropics: modular baseline health surveys. Environ Impact Assess Rev 2012, 33:15-22

21. Korenromp EL, Armstrong-Schellenberg JR, Williams BG, Nahlen BL, Snow RW: Impact of malaria control on childhood anaemia in Africa - a quantitative review. Trop Med Int Health 2004, 9:1050-1065.

22. Crawley J: Reducing the burden of anemia in infants and young children in malaria-endemic countries of Africa: from evidence to action. Am J Trop Med Hyg 2004, 71(Suppl 2):25-34

23. Naing C, Whittaker MA, Nyunt-Wai V, Reid SA, Wong SF, Mak JW, Tanner M: Malaria and soil-transmitted intestinal helminth co-infection and its effect on anemia: a meta-analysis. Trans R Soc Trop Med Hyg 2013, 107:672-683.

24. Rohner F, Zimmermann MB, Amon RJ, Vounatsou P, Tschannen AB, N'Goran EK, Nindjin C, Cacou MC, Té-Bonlé MD, Aka H, Sess DE, Utzinger J, Hurrell RF: In a randomized controlled trial of iron fortification, anthelmintic treatment, and intermittent preventive treatment of malaria for anemia control in Ivorian children, only anthelmintic treatment shows modest benefit. J Nutr 2010, 140:635-641.

25. Righetti AA, Adiossan LG, Ouattara M, Glinz D, Hurrell RF, N'Goran EK, Wegmüller $\mathrm{R}$, Utzinger J: Dynamics of anemia in relation to parasitic infections, micronutrient status, and increasing age in south-central Côte d'Ivoire. J Infect Dis 2013, 207:1604-1615.

26. Righetti AA, Glinz D, Adiossan LG, Koua AYG, Niamké S, Hurrell RF, Wegmüller R, N'Goran EK, Utzinger J: Interactions and potential implications of Plasmodium falciparum-hookworm coinfection in different age groups in south-central Côte d'Ivoire. PLOS Negl Trop Dis 2012, 6:e1889.

27. Fontenille D, Lochouarn L, Diagne N, Sokhna C, Lemasson JJ, Diatta M, Konate L, Faye F, Rogier C, Trape JF: High annual and seasonal variations in malaria transmission by anophelines and vector species composition in Dielmo, a holoendemic area in Senegal. Am J Trop Med Hyg 1997, 56:247-253

28. Hamad AA, Nugud Ael H, Arnot DE, Giha HA, Abdel Muhsin AM, Satti GM, Theander TG, Creasey AM, Babiker HA, Elnaiem DE: A marked seasonality of malaria transmission in two rural sites in eastern Sudan. Acta Trop 2002, 83:71-82.

29. Afrane YA, Klinkenberg E, Drechsel P, Owusu-Daaku K, Garms R, Kruppa T: Does irrigated urban agriculture influence the transmission of malaria in the city of Kumasi, Ghana? Acta Trop 2004, 89:125-134.

30. Ehrhardt S, Burchard GD, Mantel C, Cramer JP, Kaiser S, Kubo M, Otchwemah RN, Bienzle U, Mockenhaupt FP: Malaria, anemia, and malnutrition in African children-defining intervention priorities. $J$ Infect Dis 2006, 194:108-114.

31. Newton CR, Warn PA, Winstanley PA, Peshu N, Snow RW, Pasvol G, Marsh K: Severe anaemia in children living in a malaria endemic area of Kenya. Trop Med Int Health 1997, 2:165-178.

32. Sumbele IU, Samje M, Nkuo-Akenji T: A longitudinal study on anaemia in children with Plasmodium falciparum infection in the Mount Cameroon region: prevalence, risk factors and perceptions by caregivers. BMC Infect Dis 2013, 13:123.

33. Osorio MM, Lira PI, Batista-Filho M, Ashworth A: Prevalence of anemia in children 6-59 months old in the state of Pernambuco, Brazil. Rev Panam Salud Pública 2001, 10:101-107.

34. Noor AM, Mutheu JJ, Tatem AJ, Hay SI, Snow RW: Insecticide-treated net coverage in Africa: mapping progress in 2000-07. Lancet 2009, 373:58-67.

35. WHO: Test Procedures for Insecticide Resistance Monitoring in Malaria Vector Mosquitoes. Geneva: World Health Organization; 2013.

36. Namountougou M, Simard F, Baldet T, Diabate A, Ouedraogo JB, Martin T, Dabire RK: Multiple insecticide resistance in Anopheles gambiae s.l. populations from Burkina Faso, West Africa. PLoS One 2012, 7:e48412.

37. Edi CVA, Koudou BG, Jones CM, Weetman D, Ranson H: Multiple-insecticide resistance in Anopheles gambiae mosquitoes, southern Côte d'Ivoire. Emerg Infect Dis 2012, 18:1508-1511.

38. Koffi AA, Alou LP, Adja MA, Koné M, Chandre F, N'Guessan R: Update on resistance status of Anopheles gambiae s.s. to conventional insecticides at a previous WHOPES field site, "Yaokoffikro", 6 years after the political crisis in Côte d'Ivoire. Parasit Vectors 2012, 5:68.

39. Kleinschmidt I, Schwabe C, Shiva M, Segura JL, Sima V, Mabunda SJ, Coleman M: Combining indoor residual spraying and insecticide-treated net interventions. Am J Trop Med Hyg 2009, 81:519-524.

40. Plüss B, Tanser FC, Lengeler C, Sharp BL: Indoor residual spraying for preventing malaria. Cochrane Database Syst Rev 2010, 4:CD006657.

41. Corbel V, Akogbeto M, Damien GB, Djenontin A, Chandre F, Rogier C, Moiroux N, Chabi J, Banganna B, Padonou GG, Henry MC: Combination of malaria vector control interventions in pyrethroid resistance area in Benin: a cluster randomised controlled trial. Lancet Infect Dis 2012, 12:617-626

42. Kleinschmidt I, Torrez M, Schwabe C, Benavente L, Seocharan I, Jituboh D, Nseng G, Sharp B: Factors influencing the effectiveness of malaria control in Bioko Island, Equatorial Guinea. Am J Trop Med Hyg 2007, 76:1027-1032.

43. Asante KP, Zandoh C, Dery DB, Brown C, Adjei G, Antwi-Dadzie Y, Adjuik M, Tchum K, Dosoo D, Amenga-Etego S, Mensah C, Owusu-Sekyere KB, Anderson C, Krieger G, Owusu-Agyei S: Malaria epidemiology in the Ahafo area of Ghana. Malar J 2011, 10:211

doi:10.1186/1475-2875-13-194

Cite this article as: Knoblauch et al:: The epidemiology of malaria and anaemia in the Bonikro mining area, central Côte d'Ivoire. Malaria Journal 2014 13:194.

\section{Submit your next manuscript to BioMed Central and take full advantage of:}

- Convenient online submission

- Thorough peer review

- No space constraints or color figure charges

- Immediate publication on acceptance

- Inclusion in PubMed, CAS, Scopus and Google Scholar

- Research which is freely available for redistribution 